\title{
MODERNIZAÇÃO NO CONTROLE E MONITORAMENTO DAS TAXAS DE CORROSÃO DA ÁGUA INDUSTRIAL NA CSA COM REDUÇÃO DE CUSTOS*
}

Jocemir da Silva Santos ${ }^{1}$ Magda Moreira pinto ${ }^{2}$ Fábio Ricardo Zuege

\section{Resumo}

A água bruta captada no Canal São Francisco abastece a estação de tratamento de água (ETA) e alimenta todo o Complexo Siderúrgico da TKCSA e tem como uma das principais características de qualidade um elevado indice de corrosividade representado por milésimo de polegada por ano expressos em "mpy" devido à baixa alcalinidade e proximidades da bacia de Sepetiba sofrendo impactos da cunha salina em períodos de maré alta e redução de vazão do canal São Francisco em função de períodos de pouca chuva. A fim de evitar prejuízos aos processos e elevados custos de manutenção a TKCSA investe em controles e monitoramentos de taxas de corrosão desde a agua produzida pela estação de tratamento até a entrega aos consumidores internos, através da aplicação de produtos químicos inibidores de corrosão específicos e controle online de monitoramento de taxas de corrosão obtendo melhora na estabilização do processo e ganhos financeiros significativos com o desenvolvimento de novos fornecedores e redução de manutenção de redes de distribuição.

Palavras-chave: Corrosão; Inibidores; Ganhos.

\section{IMPROVEMENTS IN THE CONTROL AND MONITORING OF INDUSTRIAL WATER CORROSION RATES IN CSA WITH COST REDUCTION}

\begin{abstract}
The raw water extracted from the São Francisco Canal supplies the water treatment plant (WTP) and feeds the entire TKCSA Steel Complex and has as one of the main quality characteristics a high corrosion rate index represented by thousandths of an inch per year or "mpy" due to the low alkalinity of the raw water and near the ocean of the Sepetiba basin suffering impacts of the salt wedge in periods of high tide and reduction of flow of the San Francisco channel due to periods of low rainfall. In order to avoid damages to processes and high maintenance costs, TKCSA invests in controls and monitoring of corrosion rates from the water produced by the treatment plant to the delivery to internal consumers through the application of specific corrosion inhibitor and control chemicals online monitoring of corrosion rates in addition to the support of a laboratory and field team and we have had significant improvement in the stabilization of the process and significant financial gains with the development of new supplier and reduction of maintenance of distribution networks..

Keywords: Corrosion; Inhibitor; Earnings.

1 Engenheiro Químico, Engenheiro de Utilidades, Gerência de Distribuição de Utilidades, Companhia Siderúrgica do Atlântico, Santa Cruz, Rio de Janeiro, Brasil.

2 Química, Química Sênior, Gerência de Distribuição de Utilidades, Companhia Siderúrgica do Atlântico, Santa Cruz, Rio de Janeiro, Brasil.

3 Engenheiro Eletricista, Engenheiro Especialista em Distribuição de Utilidades, Gerência de Distribuição de Utilidades, Companhia Siderúrgica do Atlântico, Santa Cruz, Rio de Janeiro,
\end{abstract}




\section{INTRODUÇÃO}

Os problemas com corrosão são frequentes e ocorrem nas mais variadas atividades, como exemplo nas indústrias químicas, petrolíferas, siderúrgicas, etc, sendo que anualmente, as perdas financeiras ultrapassam bilhões de dólares em todo o mundo devido aos efeitos provocados pela corrosão sendo estas classificadas como: diretas e indiretas:

- Diretas: Custos de substituição de tubulações e equipamentos que sofreram corrosão, custos de manutenção dos processos de proteção como: pinturas, recobrimentos, etc.

- Indiretas: Limpeza em tubulações, permutadores de calor, perdas de eficiência em trocadores de calor, diminuição de vazão em linhas, alteração da qualidade da água potável distribuída nos pontos consumidores devido arraste de produtos de corrosão, etc.

Uma importante consideração é o aspecto energético, onde a obtenção do metal se faz à custa de certa quantidade de energia dos processos siderúrgicos (Vicenti Gentil, 1996).

$$
\text { Composto + Energia } \underset{\text { Corrosão }}{\stackrel{\text { Metalurgia }}{\rightleftharpoons}} \text { Metal }
$$

No conceito geral conforme figura 1, corrosão pode ser definido como a deterioração de um material, geralmente metálico, por ação química, eletroquímica do meio ambiente aliado ou não a esforços mecânicos onde o metal tende a retornar a sua condição de estabilidade.

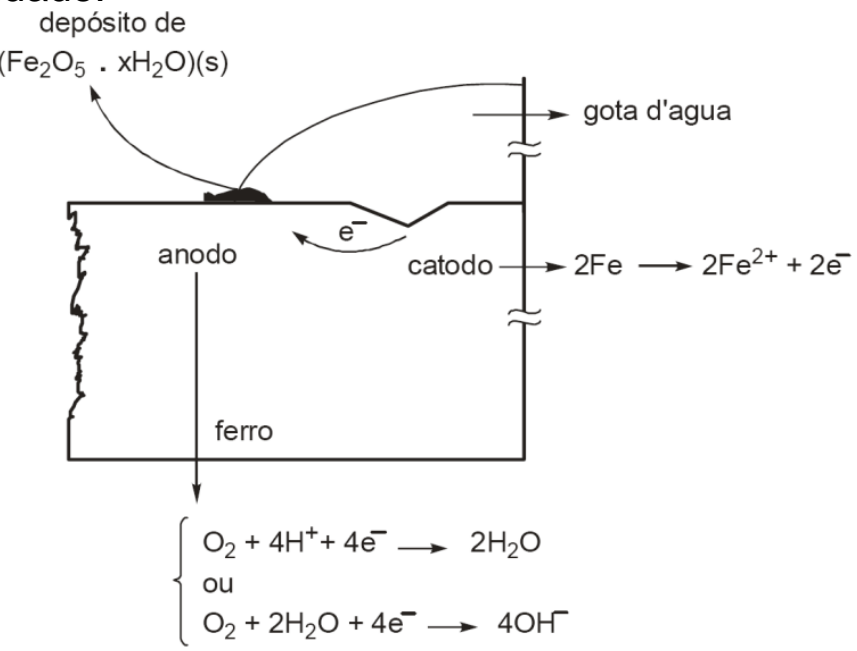

Figura 1 - Processo de corrosão

A fim de reduzir os prejuízos causados pela corrosão em tubulações e consequente riscos de paradas de processos e elevados custos, a CSA investe em controle e monitoramento de taxas de corrosão da Água Industrial distribuída a todos os seus processos, e vem investindo nos últimos anos em melhorias de desempenho conseguindo manter o processo controlado com redução de custos significativo. As variações das taxas de corrosão com e sem aplicação de inibidores de corrosão e a eficiência dos produtos aplicados são demonstrados na Tabela 1. 
Tabela 1. Taxas de corrosão com e sem aplicação de produtos inibidores de corrosão

\begin{tabular}{cccc}
\hline Meses & $\begin{array}{c}\text { Taxas de corrosão sem } \\
\text { inibidores de corrosão } \\
\text { (mpy) }\end{array}$ & $\begin{array}{c}\text { Taxas de corrosão com } \\
\text { inibidores de corrosão } \\
\text { (mpy) }\end{array}$ & $\begin{array}{c}\text { Eficiência dos produtos } \\
\text { inibidores de corrosão (\%) }\end{array}$ \\
\hline mar/15 & 42,86 & 9,85 & $77,02 \%$ \\
\hline abr/15 & 40,38 & 4,82 & $88,06 \%$ \\
\hline mai/15 & 43,74 & 7,89 & $81,96 \%$ \\
\hline jun/15 & 39,06 & 7,54 & $80,70 \%$ \\
\hline jul/15 & 30,27 & 7,95 & $73,74 \%$ \\
\hline ago/15 & 30,78 & 2,57 & $91,65 \%$ \\
\hline set/15 & 35 & 2,05 & $94,14 \%$ \\
\hline out/15 & 40,97 & 8,42 & $79,45 \%$ \\
\hline nov/15 & 33,55 & 5,08 & $84,86 \%$ \\
\hline dez/15 & 42,1 & 6,16 & $85,37 \%$ \\
\hline jan/16 & 29,34 & 13 & $55,69 \%$ \\
\hline fev/16 1 & 17,76 & & $92,50 \%$ \\
\hline mar/16 & 28 & 2,1 & $75,77 \%$ \\
\hline abr/16 & 32,6 & 7,9 & $84,23 \%$ \\
\hline mai/16 & 18,2 & 2,87 & $64,35 \%$ \\
\hline jun/16 & 10,07 & 3,59 & $96,11 \%$ \\
\hline jul/16 & 13,89 & 0,54 & $92,71 \%$ \\
\hline ago/16 & 7,13 & 0,52 & $90,72 \%$ \\
\hline set/16 & 6,79 & 0,63 & $96,20 \%$ \\
\hline out/16 & 17,89 & 0,68 & $97,57 \%$ \\
\hline nov/16 & 23,01 & 0,56 & \\
\hline dez/16 & 11,3 & 0,22 & \\
\hline jan/17 & 7,05 & 0,75 & \\
\hline $1-$ Período de transição de fornecedor. & & \\
\hline
\end{tabular}

Devido à baixa alcalinidade e as proximidades com a baia de Sepetiba, em períodos de alta maré e/ou redução de vazão no Canal de São Francisco há influência direta da salinidade aumentando o teor de cloretos na água, e por ser um eletrólito forte permite que o meio apresente baixa resistividade elétrica possibilita o fluxo de elétrons, estudo feito por Magda M. Pinto, 2014. Através do cálculo do Indice de Langelier abaixo é demonstrado as faixas de características corrosivas e de incrustações.

$$
p H s=[12,226+\log (\text { TDS }) / 13]-\log (\text { Du-Ca })-\log (\text { Alc-T })-(0,0216 \times \text { Temp) (2) }
$$

onde:

TDS=Sólidos Dissolvidos Totais em mg/L (Estimativa de TDS = Condutividade * $0,65)$

Du-Ca=Dureza Cálcio em $\mathrm{mg} / \mathrm{L}$ de $\mathrm{CaCO}_{3}$

Alc- $\mathrm{T}=$ Alcalinidade Total em $\mathrm{mg} / \mathrm{L}$ de $\mathrm{CaCO}_{3}$

Temp=Temperatura em ${ }^{\circ} \mathrm{C}$

$-2,0<-0,5$ Corrosão grave

$-0,5<0$ Ligeiramente corrosivo, mas sem formação de incrustações

$\mathrm{LSI}=0,0$ Possibilidade de corrosão equilibrada mas pitting

$0,0<0,5$ Baixa formação e corrosão

$0,5<2$ Formação de escamas mas não corrosivas 


\subsection{Objetivo}

Este trabalho busca descrever como funciona o programa de monitoramento e controle da taxa corrosão na CSA, abrangendo as principais melhorias implantadas a partir do ano de 2016 bem como a descrição dos ganhos financeiros alcançados com o desenvolvimento de novos fornecedores. Até a apresentação final dos resultados/ganhos obtidos teve as seguintes etapas:

- Estudo e aplicação dos produtos químicos;

- Elaboração de uma nova especificação técnica para o programa;

- Elaboração de concorrência no mercado;

- Avaliação técnica das empresas participantes da licitação;

- Definição da empresa ganhadora da licitação, técnica/comercial;

- Transição do antigo fornecedor para o novo fornecedor;

- Emissão dos primeiros relatórios com resultados;

- Ajustes finais.

\subsection{Programa de tratamento}

O programa de tratamento na CSA é composto das seguintes etapas:

- Inibidores de corrosão: Aplicação dos produtos químicos na rede de água industrial, que são substâncias ou misturas de substâncias que quando presente em condições adequadas no meio corrosivo reduz os efeitos da corrosão. Este controle é ajustado de acordo com a condutividade da água bruta captada e com a vazão a fim manter a taxa de corrosão dentro do limite aceitável na CSA tendo como meta ser menor do que 5 mpy (Figura 2);

$\mathrm{Na}$ escolha dos produtos inibidores de corrosão foi levado em consideração: sua alta solubilidade, baixa degradabilidade, faixa de $\mathrm{pH}$, disponibilidade no mercado, alto teor de ativos, baixo custo do mercado, eficiência e riscos ambientais.

- Monitoramento da Corrosão por Corpos de Prova e Sondas Corrosimétricas:

Até 0 ano de 2015, o monitoramento era feito por análises de taxas de corrosão mensais dos cupons de corpo de prova na saída da estação de tratamento de água sem aplicação dos inibidores de corrosão e dentro das áreas após a aplicação dos inibidores de corrosão.

A partir de fevereiro de 2016 foi implantado o monitoramento online de taxas de corrosão, Figura 2, na saída do tratamento de água, monitoramento de taxas de corrosão nas áreas por sondas corrosimétricas, Figura 3, e alteração dos tipos de bombas de dosagens com aplicação em função da vazão de água.

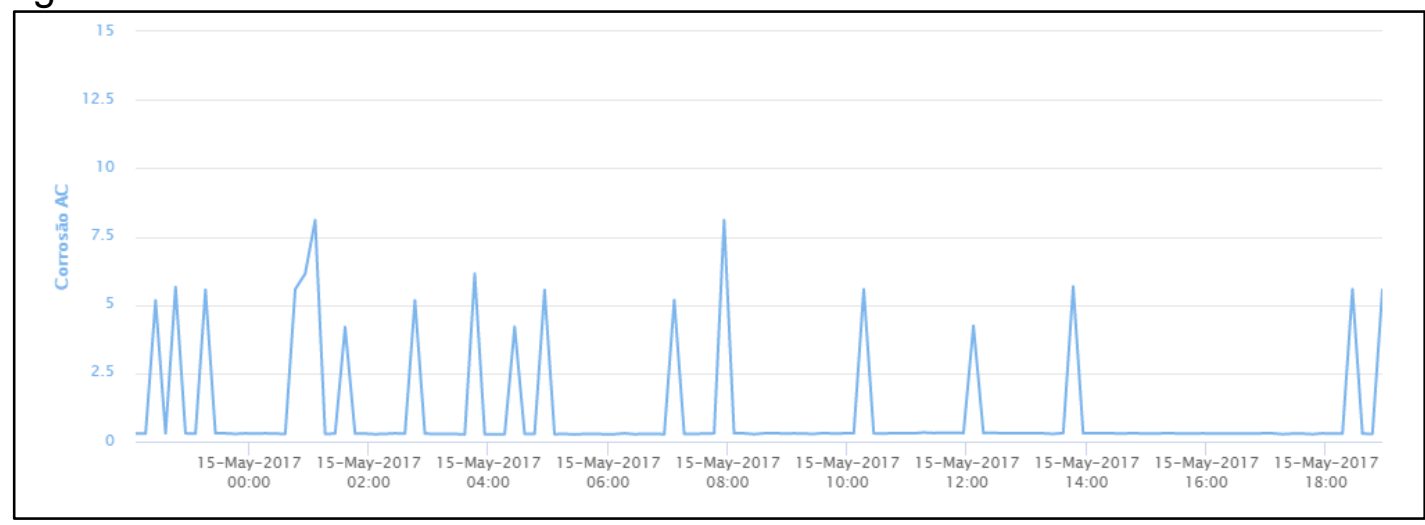

Figura 2 - Monitoramento online de taxas de corrosão 


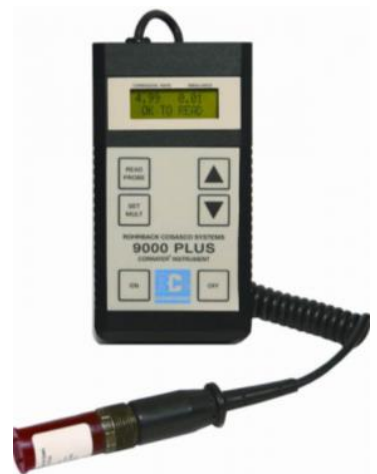

Figura 3 - Equipamento de análises de taxas de corrosão instantânea

- Controle analítico da água: O monitoramento é feito por laboratório interno que realiza periodicamente as análises químicas de Ferro total e solúvel, $\mathrm{pH}$, condutividade, turbidez, sólidos totais dissolvidos, fosfato, zinco, alcalinidade, dureza total, sílica, cálcio, magnésio, alumínio e outros.

- Custo: É feito o acompanhamento do consumo mensal de produtos químicos a fim de certificar que as quantidades estão sendo aplicadas corretamente, além disso, este trabalho esta incluso no programa interno de redução de custos da CSA.

\section{MATERIAIS E MÉTODOS}

\subsection{Cupons de corpo de prova:}

Materiais: Placa, tubulação, válvulas, adaptadores, cupom de corpo de prova metálico.

Método: Fluxo contínuo de água passando por um corpo de prova metálico.

Pesagem do cupom de corpo de prova metálico antes e após a exposição de 30 dias a fim de medir a massa perdida. Conforme a NACE Standard TM-01-69

\subsection{Sonda Corrosimétrica}

Materiais: Sonda, adaptador para sonda, tubulação, equipamento portátil.

Método: Medição da variação da resistência elétrica provocada pela redução da seção transversal do elemento sensor devido ao processo corrosivo.

\subsection{Qualidade da Água}

Para medições dos teores de ferro total e solúvel.

Materiais: Espectrofotômetro UV-VIS.

Método: Espectrofotométrico. 


\section{RESULTADOS E DISCUSSÃO}

\subsection{Processo}

Através do "Portal de Utilidades (Figura 4)" é feito o acompanhamento dos principais parâmetros analíticos de acompanhamento do processo de controle de corrosão na CSA no qual, a análises de ferro expresso em "mg/L", é o principal deles, pois serve para verificação direta de como está o processo corrosivo das redes de água industrial. É utilizado a plataforma PIMS para acompanhamento por gráficos dos resultados analíticos dos principais parâmetros e elaboração de histogramas.

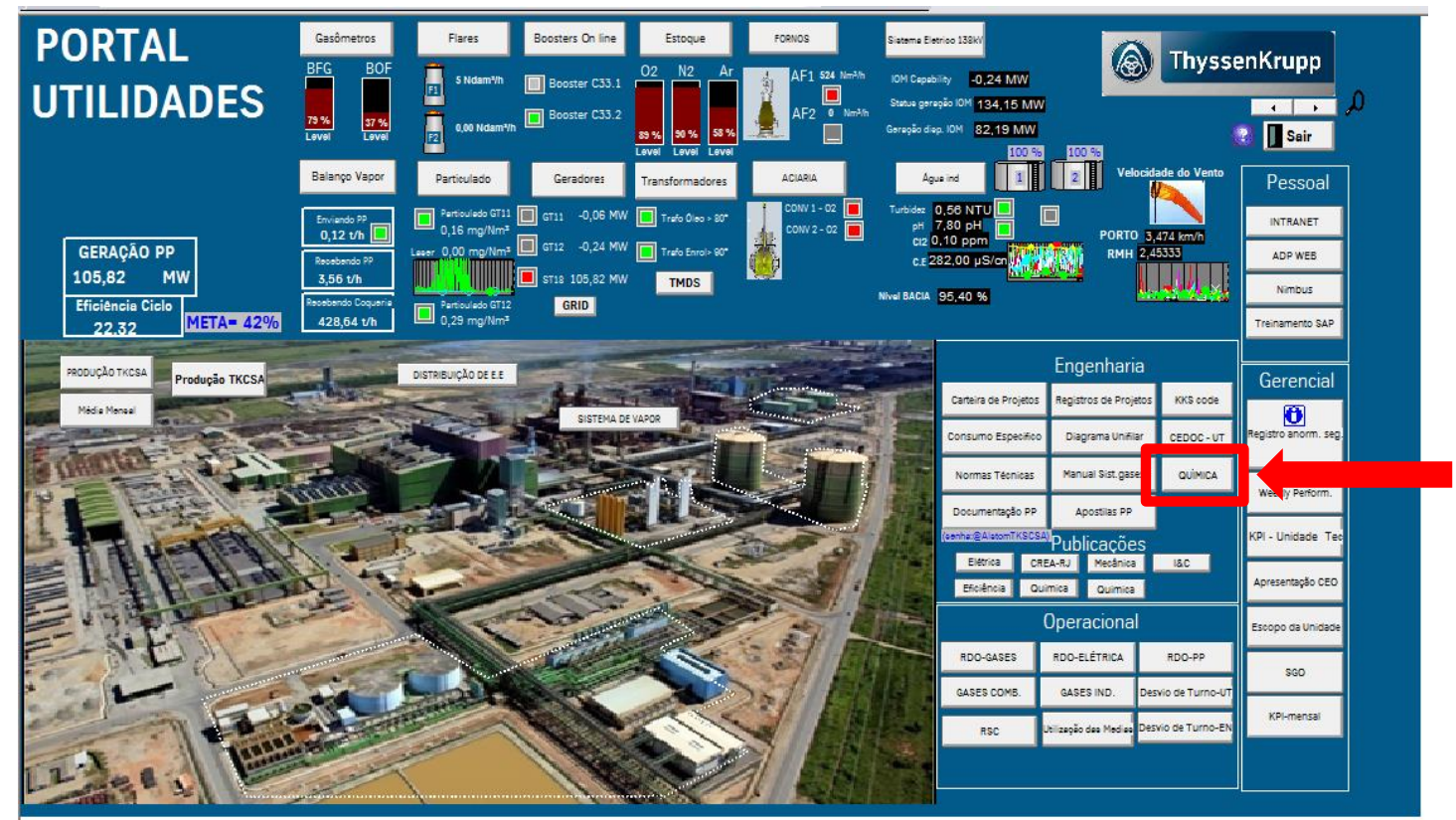

Figura 4 - Portal de Utilidades [2]

As figuras 5, 6, 7 e 8 apresentam os teores de ferro total nas áreas.
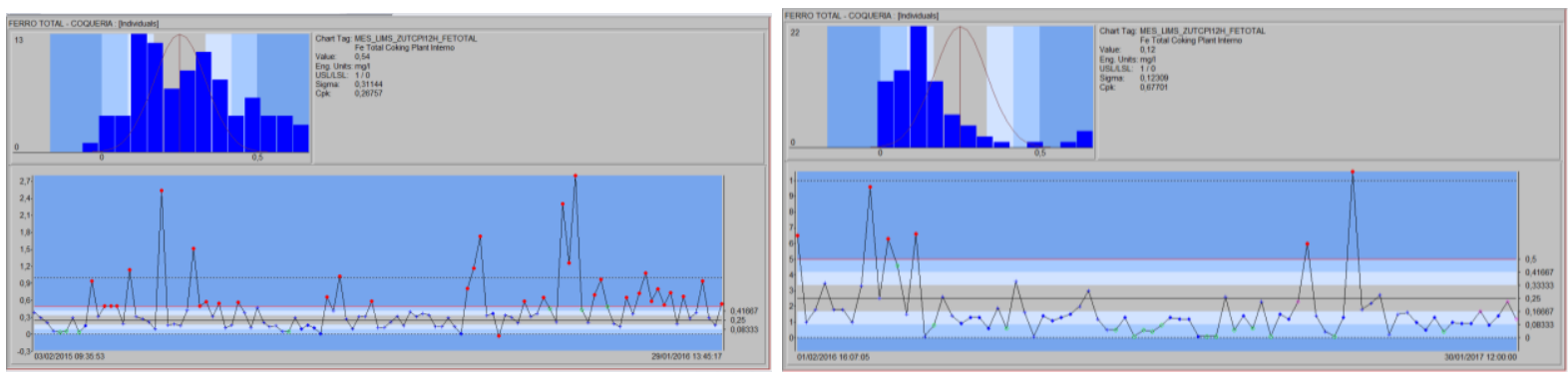

Figura 5 - Teor de ferro na Coqueria antes e depois das melhorias implantadas
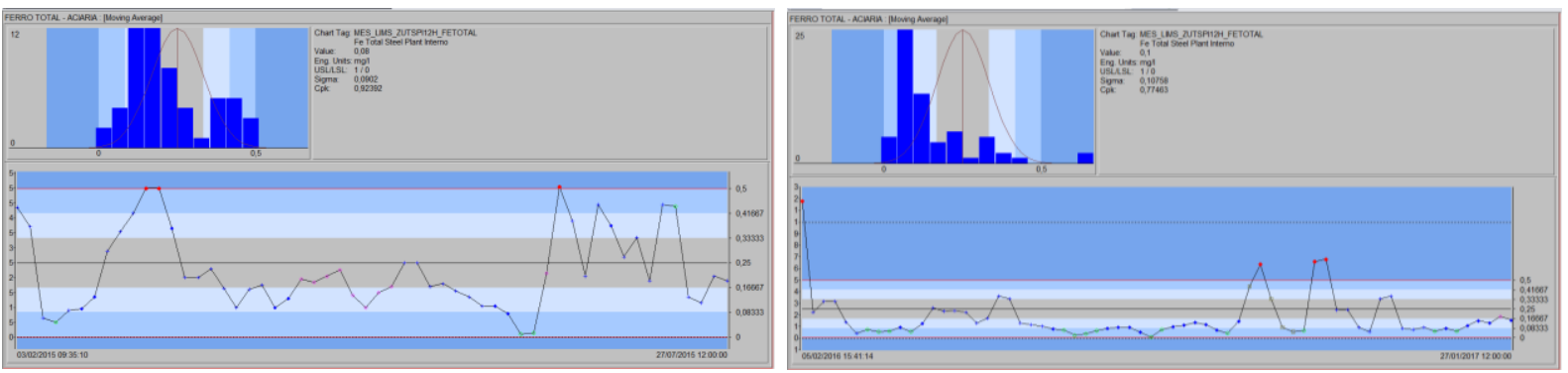

Figura 6 - Teor de ferro na Aciaria antes e depois das melhorias implantadas 

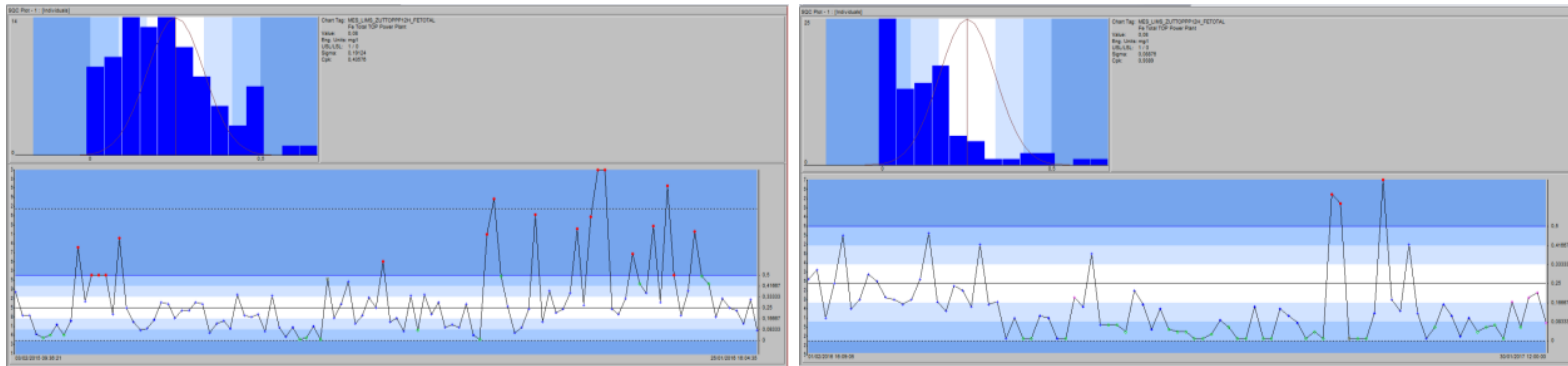

Figura 7 - Teor de ferro na Termelétrica antes e depois das melhorias implantadas
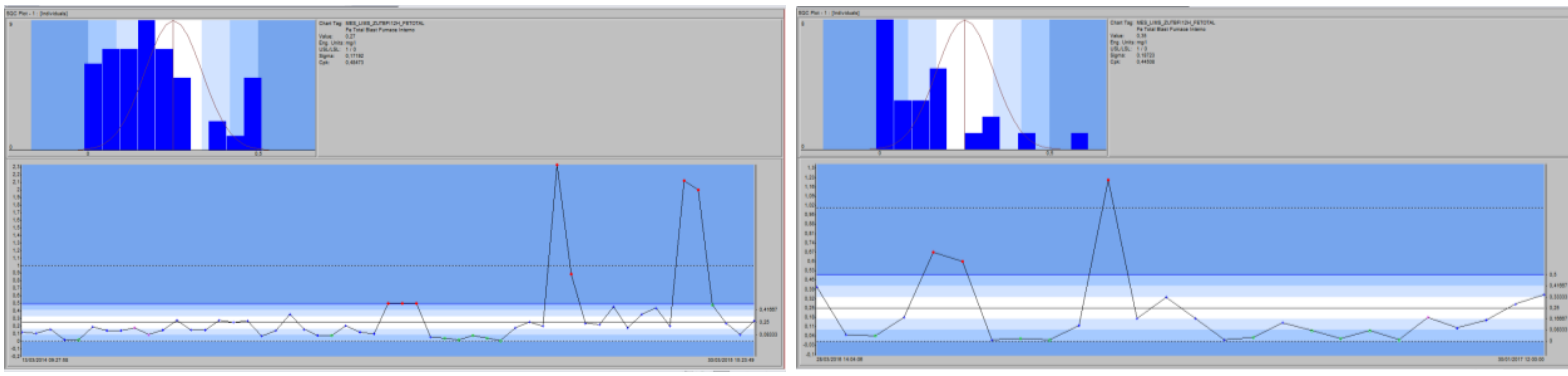

Figura 8 - Teor de ferro no Alto Forno antes e depois das melhorias implantadas

Também é feito o acompanhamento do Indicador de performance (KPI) do programa de controle e monitoramento que é a medição de taxas de corrosão, expresso em "mpy", conforme figura 9.

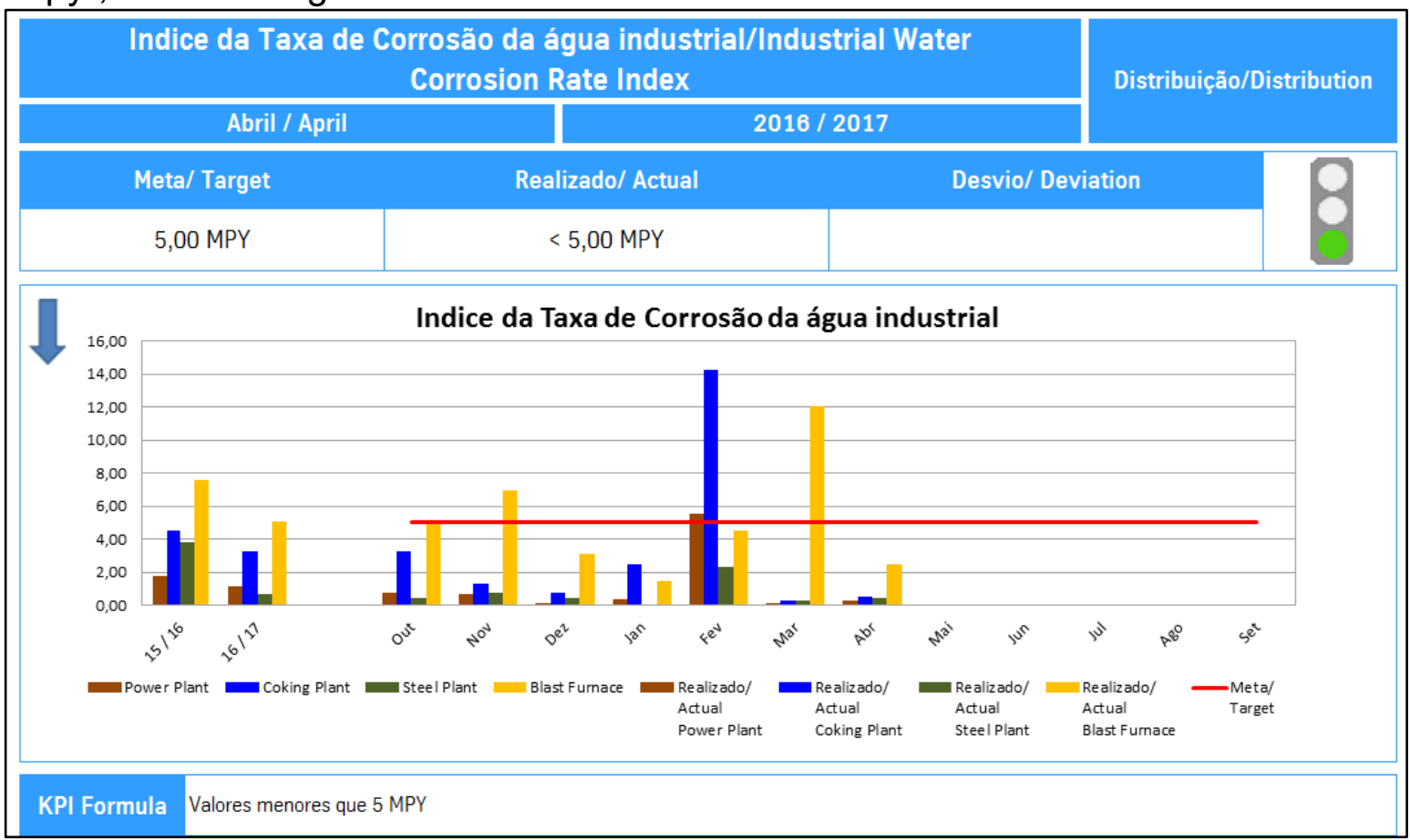

Figura 9 - Indicador de performance (KPI) - índice de Taxa de Corrosão da água industrial

Verifica-se na figura 5 que o teor de ferro total na área da Coqueria apresentou valores de $69 \%$ abaixo de $0,50 \mathrm{mg} / \mathrm{L}$ no período de fev./2015 a fev./2016 e de $95 \%$ abaixo de 0,50 mg/L no período de fev./2016 a fev./2017. 
Na figura 6, é demonstrado que a área da Aciaria os resultados de ferro total ficaram em $88 \%$ no período de fev./2015 a fev./2016 e de $91 \%$ no período de fev./2016 a fev./2017.

Na figura 7, a área da Termelétrica apresentou resultados de ferro total conformes de $68 \%$ no período de fev./2015 a fev./2016 e de 97\% no período de fev./2016 a fev./2017.

Na figura 8, o teor de ferro total menor que $0,50 \mathrm{mg} / \mathrm{L}$ na área dos Altos Fornos apresentaram valores de $89 \%$ e $88 \%$, quando comparado o período de fev./2015 a fev./2016 e fev./2016 a fev./2017 respectivamente.

Na figura 9, é demonstrado o principal indicador para este processo, que é o indice de taxa de corrosão, onde são demonstrados valores bem abaixo da meta (5 MPY). $\mathrm{Na}$ área dos Altos Fornos tivemos valores acima da meta no mês de Novembro de 2016 em função da interrupção do fluxo de água de monitoramento em função de uma parada para manutenção geral nos equipamentos dos Alto Fornos, comprometendo o resultado.

Na figura 9, vemos que os resultados de taxas de corrosão nas áreas estão abaixo do limite controle de 5,0 mpy, com um desvio no mês de novembro de 2016 na área do Alto Forno com valor próximo de 7,0 mpy em função de paradas para manutenção e que volta ao limite de controle no mês de dezembro.

A eficiência do tratamento também é medidor através da avaliação de eficiência dos produtos inibidores de corrosão através da Equação 3, informados na Tabela 1.

onde:

$$
E f=\frac{T s}{T c} x 100(3)
$$

Ef = eficiência em percentual

Ts = taxa de corrosão sem uso do inibidor

Tc = taxa de corrosão com uso do inibidor

\subsection{Custos}

A figura 10 abaixo demonstra os ganhos financeiros mês a mês alcançados com a melhoria do programa e desenvolvimento de novo fornecedor quando comparados os meses de fevereiro a janeiro do ano fiscal 2015/16 aos meses de fevereiro a janeiro de 2016/17. 


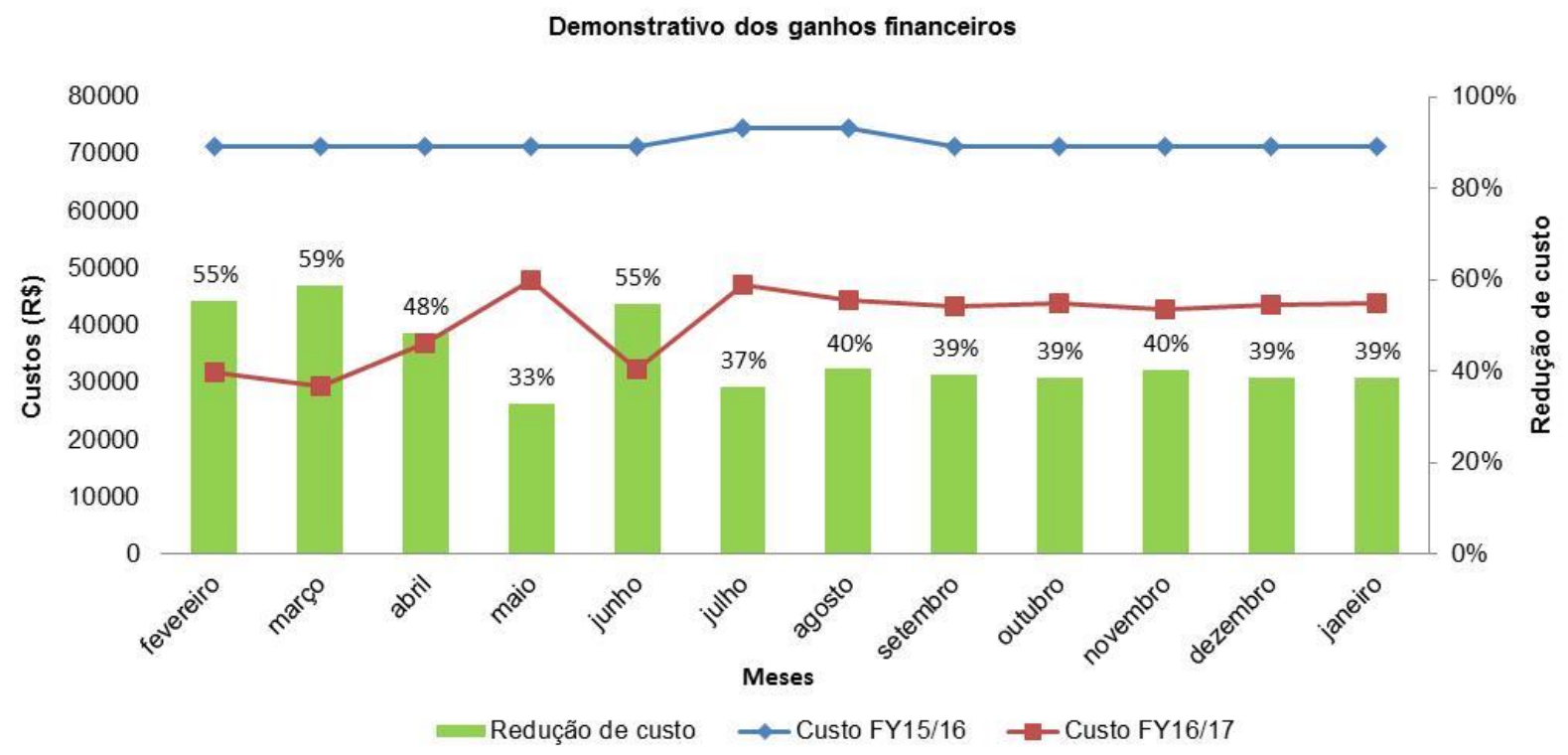

Figura 10 - Demonstrativo de ganhos financeiros com o programa

Nos primeiros meses de implantação das melhorias com o programa fevereiro, março e abril de 2016, foi verificado uma redução de custos expressiva de $55 \%$, $59 \%$ e $48 \%$, respectivamente, quando comparado com o mesmo período do ano anterior. Isto se deve basicamente a ajustes nos sistemas de dosagens e problemas de manutenção de equipamentos e vazamentos que ocorreram, porém, verifica-se que nos meses subsequentes há uma estabilização do processo e as reduções de custos atingiram patamares próximos de $40 \%$.

\section{CONCLUSÃO}

Pelo presente trabalho foi demonstrado que a CSA teve uma melhora significativa no controle e monitoramento de taxas de corrosão implantadas em 2016 quando comparadas ao ano de 2015. O programa demonstra eficiência dos inibidores de corrosão em média de 90\% em 2016 e em torno de 81\% em média no ano de 2015 com incremento de $9 \%$ em eficiência, houve também um aumento significativo dos resultados de ferro total conformes em algumas áreas, atingindo patamares de mais de $90 \%$ dentro dos limites de controle quando comparados ao mesmo período. Além disso, houve uma economia financeira média com o programa de tratamento de $40 \%$ no ano de 2016 quando comparado ao ano de 2015.

Como boas práticas, as estações de corpos de provas das áreas utilizadas neste trabalho faz parte do programa de reutilização de água da CSA. No qual esta água utilizada nos sistemas de monitoramento das taxas de corrosão é reutilizada nos processos internos.

\section{Sugestões de melhorias:}

Com base nos resultados obtidos foi observada a necessidade de projetos de melhoria na área do Alto Forno a fim de garantir a estabilidade do processo. 


\section{Agradecimentos}

A Thyssenkrupp CSA pela oportunidade de estudar, implementar e divulgar este trabalho. E a todos da equipe envolvidos que contribuíram para realização do mesmo.

\section{REFERÊNCIAS}

1 Célia Alves. Tratamento de águas de abastecimento. 3a Edição. Portugal, 2005

2 Claudio José Martins da Silva, Elio Souza Portes, Alessandro Andrade Maia. PORTAL UTILIDADES - UMA FERRAMENTA PARA GESTÃO OPERACIONAL USANDO O PIMS NA TKCSA. 2015;5

3 Pinto, M. M; Sabino, C.V.S; Laje, L.V. Estudo da relação entre a altura da maré e a salinidade nas águas do canal São Francisco captada pela Thyssenkrupp CSA, utilizando técnicas multivariadas robustas. XIV CBL Congresso Brasileiro de Limmologia, 2014, Bonito - MS

4 Vicenti Gentil. Corrosão. 3a Edição. Rio de Janeiro. Livros Técnicos e Científicos LTC; 1996

5 Water Treatment Solutions [página da internet], Holanda: [acesso em 10 mai. 2017]. Disponível em: http://www.lenntech.com 